\title{
Synthesis of Al- Sic Composite Prepared By Mechanical Alloying
}

\author{
*Charanjit Singh ${ }^{1} \&$ *Jagteshwar Singh ${ }^{2}$ \\ ${ }^{1}$ Assistant Professor, Department of Mechanical Engineering, Surya School of Engineering and \\ Technology,Bapror, NH-1, Shambhu, Punjab, \\ ${ }^{2}$ Assistant Professor, Department of Mechanical Engineering, Surya School of Engineering and Technology, \\ Bapror, NH-1, Shambhu, Punjab,
}

\begin{abstract}
Aluminium matrix composites (AMCs) refer to the class of light weighthigh performance aluminium centric material systems. Properties of AMCs can bepersonalized to the demands of special industrial applications by appropriate combinationsof matrix, reinforcement and processing technique.

The widespread acceptance of particulate metal matrixcomposites for engineering applications has been hindered by the high cost of producingcomponents. Although several technical challenges exist with casting technology yet it can beused to overcome this problem. Achieving a uniform distribution of reinforcement within thematrix is one such challenge, which affects directly on the properties and quality of compositematerial. In the present reading a modest effort has been made to develop aluminium basedsilicon carbide particulate MMCs with an objective to develop a conventional low cost technique ofproducing MMCs and to obtain homogenous dispersion of ceramic material. To achieve theseobjectives Mechanical alloying method of powder metallurgy has been adopted and consequentproperty analysis has been made. Experiments have been conducted by varyingweight fraction of $\mathrm{SiC}(4 \%, 6 \%, 8 \%$ and10\%), while keeping all other parametersconstant. Friction and wear characteristics of Al-SiC composites have been investigated under dry sliding conditions. Dry sliding wear tests have been carried out using pin-on-disk wear test rate normal loads of 10,20,30,40 and 50N and at constant sliding velocity of $1.6 \mathrm{~m} / \mathrm{s}$.

The results show that the 'developed method' is moderately successful to attain uniformdispersion of reinforcement in the matrix. An increasing trend of hardness with increase in weight percentage of SiC has been observed. It was found from the testing that the wear rate decreases linearly with increasing weight fraction of silicon carbide.
\end{abstract}

Keywords: $A M C s, M M C s, M A, A l, S i C$

\section{Introduction}

Scientific investigations by materials scientists have been continuously directed towards improving the properties and performance of materials. Significant improvements in mechanical, chemical, and physical properties have been achieved through chemistry modifications and conventional thermal, mechanical, and thermo-mechanical processing methods. However, the ever-increasing demands for "hotter, stronger, stiffer, and lighter" than traditional materials have led to the design and development of advanced materials. The hightechnology industries have given an added stimulus to these efforts.[2]

Aluminium alloy materials or simply composites are combinations of materials. They aremade up of combining two or more materials in such a way that the resulting materials havecertain design properties on improved properties. The Aluminium alloy composite materialsconsist of high specific strength, high specific stiffness, more thermal stability, morecorrosion and wear resistance, high fatigue life.[1]

MMC's are either in use or prototyping for the space shuttle, commercial airliners, electronic substrates, bicycles, automobiles, golf clubs, and a variety of other applications.Aluminium based composite materials are leading ones in this area; they are fabricated using many methods, including powder metallurgy processes.[3]

Mechanical alloying (MA) is a solid-state powder processing technique involving repeated welding, fracturing, and rewelding of powder particles in a high-energy ball mill. Mechanical alloying is a unique process for fabrication of several alloys and advanced materials at room temperature. The Mechanical alloying process was developed in 1966 at The International Nickel Company (INCO) as part of a program to produce a material combining oxide dispersion strengthening with gamma prime precipitation hardening in a nickel-based super alloy intended for gas turbine applications. In fact, the original Mechanical alloying process was the by-product of research into different subjects. [2]

In the present work, an effort has been made to study hardness and wear properties with varying weight fraction of $\mathrm{SiC}$ in particle reinforced MMCs developed with the help of mechanical alloying method of powder metallurgy technique. The behavior of the composite was studied by using a Pin on Disk machine. 


\section{Experimental Procedure}

Under the following parameters the present experimentation was performed [2]:

$>$ Type of mill: High-energy mill (Attrition Ball Mill)

$>$ The material of milling tool: Stainless steel

$>$ Type of milling media: Balls

$>$ Milling atmosphere: Air

$>$ Milling environment: Dry milling

$>$ Milling media-to-powder weight ratio: 10:1

$>$ Milling time: $7 \mathbf{h r}$ per sample

\section{Raw Materials}

The aluminium and silicon carbidepure powders were acquired from Nice Chemical Pvt. Ltd. (Cochin) India that has particle sizes in the range of 200 Mesh. . But, the powder particle size is not very serious, except that it should be smaller than the grinding ball size. This is because the powder particle size decreases exponentially with time and reaches a small value of a few microns only after a few minutes of milling.

\section{Sample Preparation}

Equivalent quantities of the metal powders were taken by weight. The weighing was done in a very precise weighing balance. $200 \mathrm{gm}$ batches were prepared for each sample.

Sample A $(\mathrm{Al}-96 \%, \mathrm{SiC} 4 \%)$

The quantities of the metal powder as:

$\mathrm{Al}=192 \mathrm{gm}, \mathrm{SiC}=8 \mathrm{gm}$

Sample C (Al-92\%, SiC 8\%)

The quantities of the metal powder as:

$\mathrm{Al}=184 \mathrm{gm}, \mathrm{SiC}=16 \mathrm{gm}$
Sample B ( $\mathrm{Al}-94 \%, \mathrm{SiC} 6 \%)$

The quantities of the metal powder as: $\mathrm{Al}=188 \mathrm{gm}, \mathrm{SiC}=12 \mathrm{gm}$

Sample D ( $\mathrm{Al}-88 \%, \mathrm{SiC} 10 \%)$

The quantities of the metal powder as:

$\mathrm{Al}=180 \mathrm{gm}, \mathrm{Al}_{2} \mathrm{O}_{3}=20 \mathrm{gm}$

\section{Ball Milling}

The milling procedure takes place by the stirring action of an agitator which has a vertical rotating central shaft with horizontal impellers of Attritor used for the Mechanical alloying process. The rotation speed of the central shaft is about $100 \mathrm{rpm}(4.2 \mathrm{~Hz})$.

The morphology of the powders is tailored when they are subjected to ball collisions. The initial ballpowder-ball collision causes the ductile metal powders to flatten and work harder when they are cold welded and heavily mechanically deformed. Milling results in cold welding and deformation of the layered particles and a refined microstructure is obtained. It also helps in making the powder uniform.

\section{Sieving Of Powder}

Sieve analysis was done on each powder and general fineness number was calculated. Grain particles ranging from 0 to $100 \mu \mathrm{m}$ were to be used reinforcement. So $100 \mu \mathrm{m}$ was used to sieve both the powders. After sieving, Aluminium and silicon carbide powder was of the range of 50 to $100 \mu \mathrm{m}$.

\section{Preparation Of Compact} Die Design \& Fabrication

As abrasion wear rate test was to be performed on compacts, sodie of circular cross-section was prepared. The die is shown in Fig. 1. Material used for manufacturing of die is hot die steel.

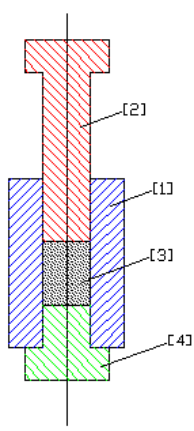

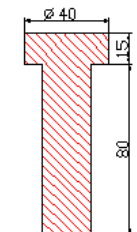

[2]

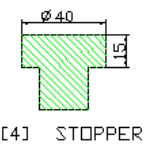

Fig. 1 Die $[8]$

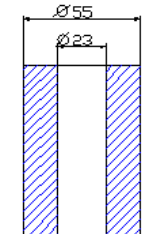

[1] DIE

[3] CDMPOSITE PLWDER 


\section{Compaction of Metal Matrix Composite}

Compaction of the samples was done on a manually operated hydraulic press \& floating circular crosssection die as shown in Fig. 2. The specimens were hard-pressed using pressure of $2 \mathrm{MPa} \&$ at room temperature for $2 \mathrm{~min}$.

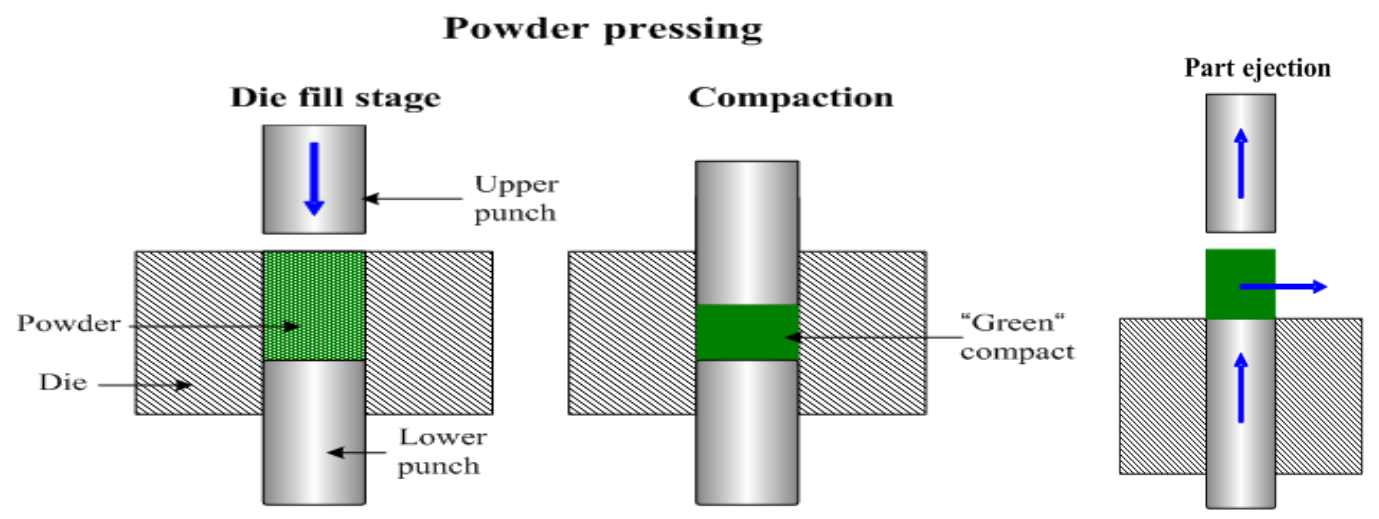

Fig. 2Powder Pressing [8]

\section{Sintering}

Sintering was donein a horizontal tube electric furnace with a high purity hydrogen (inert) environment for $1 \mathrm{hr}$. The hydrogen flow rate was $1.5 \mathrm{l} / \mathrm{min}$. The sintering temperature was kept at $530^{\circ} \mathrm{C}$.All the samples were sintered simultaneously.

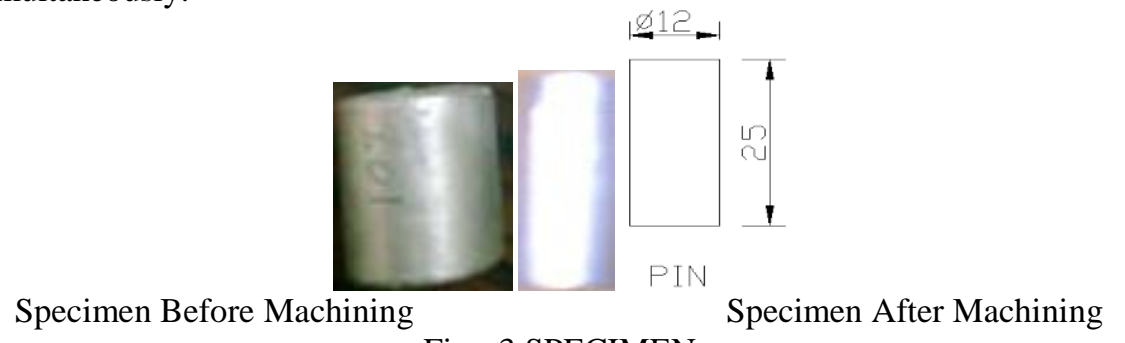

Fig. -3 SPECIMEN

\section{Samples Testing}

\section{A) Wear Testing of Al-SiC Composite}

Dry sliding wear tests for the Al-SiC have been conducted using pin-on-discmachine. The tests have beenconducted in air. The specimen is held stationary against the counter face of a $60 \mathrm{~mm}$ diameter rotating disc made of En-32 steel. The wear tests have been conducted under the fivenormal loads 10, 20, 30, 40\&50 N and at fixed sliding speed of $1.6 \mathrm{~m} / \mathrm{s}$. Each wear test has beencarried out for a $30 \mathrm{~min}$. Thepin is removed from the holder after each run, properly cleaned using acetone.

\section{B) Hardness Testing of Al-SiC Composite}

Specimens of size $\Phi 12 \mathrm{~mm} * 3 \mathrm{~mm}$ were prepared and polishing operation was done. The specimens were rubbed by emery paper of grade 100,200,500, and 650 in increasing order. When mirror like surface was obtained,etching was done on the specimens using $10 \% \mathrm{NaOH}$ solution. Then hardness test was performed on all the specimens.

\section{Wear strength testing results of Al-SiC Composite}

\section{Results And Discussion}

The results of all the fourspecimens are shown in Fig. 4 to 7 . The results show that with increase of SiC content, the wear strength increases. 

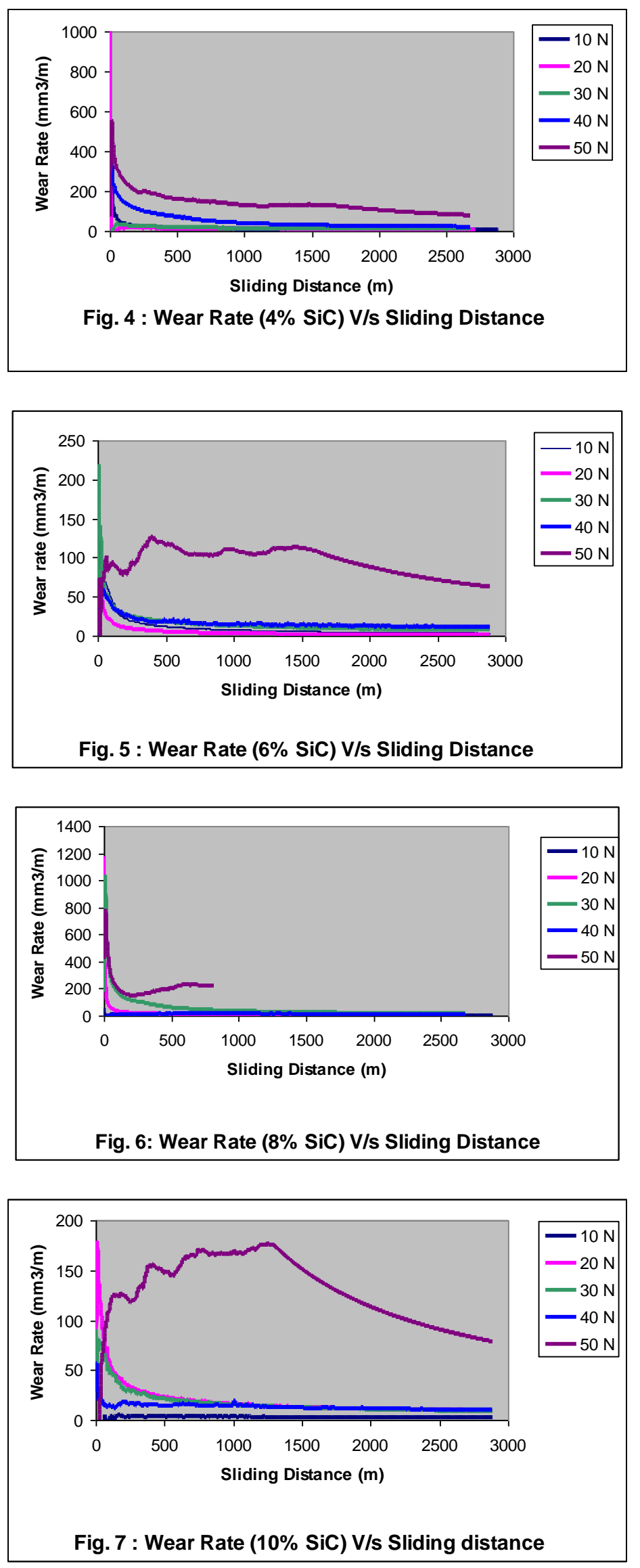
From the Figures4 to 7exhibiting wear rate v/s sliding distance for different $\%$ of $\mathrm{SiC}$, and various curves obtained it is clear that as the $\%$ of $\mathrm{SiC}$ increases wear rate decreases. All the curves for different $\%$ of $\mathrm{SiC}$ show immediate rise in wear behaviour at the starting. The reason for this may be the contact stresses due to which unsteadiness of the foam of samples occurred. For more than $6 \%$ of SiC the wear behaviour shows the identical variations, however $4 \%$ of $\mathrm{SiC}$, the wear behaviour is slightly different that may be due to some extraneous factors in experimentations.

\section{Hardness}

In Table 1, Fig.8the hardness shows the variation with $\%$ of SiC. It is clear from the picture (Fig.8) that as the \% of $\mathrm{SiC}$ increases in aluminium, hardness of the sample's increases on HRB scale.

\begin{tabular}{|c|c|}
\hline & \\
$\mathrm{SiC}(\%)$ & HARDNESS (HRB) \\
\hline 4 & 46.0 \\
\hline 6 & 58.1 \\
\hline 8 & 59.3 \\
\hline 10 & 62.5 \\
\hline
\end{tabular}

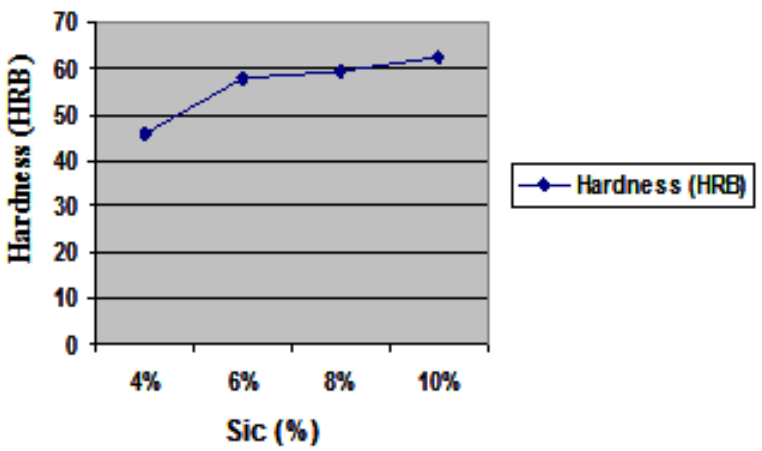

Table.1 Value of Hardness \&SiC (\%)Figure 8: Hardness (HRB) V/s SiC (\%)

\section{Conclusion}

Knowing the advantageous influence of mechanical alloying on the tribological properties of aluminum matrix composites, we produced $\mathrm{Al}$ - SiC composites, by powder metallurgy using mechanical alloying.

During the present examination it was found that the SiCcontents were able to improve the wear rate (Fig. 4-7), hardness (Fig. 8) of aluminum composite produced by powder metallurgy using mechanical alloying by Attritor mill.

\section{References}

[1]. Neelima Devi.C, Mahesh.V, Selvaraj.N (2011), "Mechanical characterization of Aluminium silicon carbide composite", International Journal of Applied Engineering Research, Dindigul, Volume 1, No 4, ISSN 0976-4259

[2]. C. Suryanarayana, (2001)," Mechanical alloying and milling”, Progress in Materials Science 46, 1-184

[3]. M. Kathiresan and T. Sornakumar (2010), "EDM Studies on Aluminum Alloy-Silicon Carbide Composites Developed by Vortex Technique and Pressure Die Casting", Journal of Minerals \& Materials Characterization \& Engineering, Vol. 9, No.1, pp.79-88

[4]. M K Surappa (2003), "Aluminium matrix composites: Challenges andOpportunities", SadhanaVol. 28, Parts 1 \& 2, February/April, pp. 319-334

[5]. Mark Occhionero, Richard Adams, and Kevin Fennessy, "A New Substate For Electronics Packging: Aluminium-Silicon Carbide (AlSiC) Composites", Proceedings of the Forth Annual Portable by Design Conference, Electronics Design, March 24-27, pp 398403

[6]. Manoj Singla, D. Deepak Dwivedi, Lakhvir Singh, Vikas Chawla (2009), "Development of Aluminium Based Silicon Carbide ParticulateMetal Matrix Composite", Journal of Minerals \& Materials Characterization \& Engineering, Vol. 8, No.6, pp 455-46

[7]. Manoj Singla, Lakhvir Singh, Vikas Chawla (2009), "Study of Wear Properties of Al-SiC Composites", Journal of Minerals \& Materials Characterization \& Engineering, Vol. 8, No.10, pp.813-819

[8]. Atul Aggarwal and Lakhbir Singh (2011), "Synthesis and Tribological Characterization ofAluminium-Alumina Composite Powder byMechanical Alloying”, International Journal of Advanced Materials ScienceISSN 2231-1211 Volume 2, Number 3, pp. 279-292

[9]. Yilmaz O., Buytoz S. (2001)," Abrasive wears $\mathrm{Al}_{2} \mathrm{O}_{3}$ - reinforced aluminium based MMCs", composites Science Technology 61, 2381-2392

[10]. Dobrzanski, L.A., Wlodarczyk, A., Adamiak, M.(2008), "ManufacturingAluminium Matrix Composite Materials Reinforced by $\mathrm{Al}_{2} \mathrm{O}_{3}$ Particles", 27, 99-102

[11]. Kwok J. K. M. (1994), “ Effect of Mechanical Alloying on the Friction and Wear Characteristics of Al-4.5Cu-15SiC Particulate Composites”, International Tribology Conference Austrib' 94, Perth, 5-8. December, pp 241-247

[12]. Dobrzanski, L.A., Wlodarczyk, A., Adamiak, M. (2005),"The Structure and Properties of PM Composite Materials based on EN AW-2124 Aluminium Alloy Reinforced with the $\mathrm{BN}$ or $\mathrm{Al}_{2} \mathrm{O}_{3}$ Ceramic Particles", J. Material Process Technology 162-163, 27-32

[13]. Goda, T., Varadi, K., Friedrich, K., Giertzsch, H.(2002), "Finite Element Contact, Strain Stress Analysis of Differently Oriented Fiber-Reinforced Polymer Composites subjected to a sliding steel asperity", part 1; normal fiber orientation, J. material Science, 37: 1575-1583

[14]. Joshna P., Ashkenazi D., Ganor M.(2000), “The Influence of a Third Element on the interface reactions in Metal Matrix Composites (MMC) Al-Graphite system",Materials Sci. Engg A V 281, (1-2): 239-247

[15]. Chen. M.Y., (2002), "Friction Behaviour of co- continuous Alumina/Aluminium Composites with \& without SiC Reinforcement", Wear, Vol. 249, pp. 868-876 
[16]. Mares, M. (2001), "Some Issues on Tailoring Possibilities for Mechanical Properties of Particulate Reinforced Metal Matrix Composites" Journal of Optoelectronics and AdvancedMaterials, Vol. 3 (1), pp. 119 - 124

[17]. Doel.T.J.A, Lorretto.M.H and Bowen.P. (1993), "Mechanical Properties ofaluminium based particulate metal matrix composites", Journal of composites, 24,pp. 270275

[18]. Gnjidi, X., Boi, D. and Mitkov, M. (2001), "The Influence of SiC Particles on Compressive Properties of Metal Matrix Composites", Materials Characterization,147(2), pp. 129138

[19]. Mark Occhionero, Richard Adams, Kevin Fennessy, and Robert A. Hay (1998), "Aluminum Silicon Carbide (AlSiC) for Advanced Microelectronic Packages", IMAPS May, Boston Meeting, Ceramics Process Systems Corp 